\title{
Editorial: Water Resources Management in a Changing World: Challenges and Opportunities
}

\author{
Gokmen Tayfur ${ }^{1} \cdot$ Bihrat Onoz $^{2}$ • \\ Antonino Cancelliere $^{3} \cdot$ Luis Garrote ${ }^{4}$
}

Published online: 5 January 2017

(C) Springer Science+Business Media Dordrecht 2017

\begin{abstract}
Although the science of water management has experienced significant improvements over the past century, many issues still require the attention of the scientific community. Global change, growing population and increasing pressure on existing water supplies have intensified the need for further improvement of water resources management practice. The purpose of this special issue is to present some of the latest research carried out in the area of water resources management under uncertain and changing conditions. Articles in this issue highlight recent advances in this area covering all the aspects of the hydrologic cycle.

The articles in this special issue were submitted to Water Resources Management in response to an invitation by the scientific committee of the 9th World Congress of the European Water Resources Association held in Istanbul on 10-13 June 2015. A total of 31 contributions were invited among those presented in the congress and 19 papers were accepted for publication following the guidelines and standard review procedures of Water Resources Management. Articles contributed to this special issue are organized in three principal categories, each represented by a group of papers. A first category of papers deals with innovative tools and techniques for the analysis of complex hydrological processes that develop in space and time. The second group of papers deals with hydrologic extremes: floods and droughts, emphasizing the need to incorporate uncertainty and risk issues. The last category covers the challenges to the implementation of water resources management to solve practical problems, highlighting the importance of new approaches to face emerging challenges.
\end{abstract}

Luis Garrote

1.garrote@upm.es

1 Department of Civil Engineering, Izmir Institute of Technology, Urla, Izmir, Turkey

2 Department of Civil Engineering, Istanbul Technical University, Maslak, İstanbul, Turkey

3 Department of Civil Engineering and Architecture, University of Catania, Catania, Italy

4 Department of Civil Engineering: Hydraulics, Energy and Environment, Technical University of Madrid, Madrid, Spain 
This special issue begins with a section on hydrological processes and their impact on water management. The topics covered in the six articles in this section range from climate-driven processes linked to precipitation to groundwater flow. The section starts with the contribution by Papageorgaki and Nalbantis 2016, "Classification of Drainage Basins Based on Readily Available Information ", which deals with the classification of drainage basins according to climate-based variables and geomorphometric characteristics. Application of the methodology to several basins in Greece shows the validity of the approach, which can find useful application in transferring hydrological information, for instance in predicting streamflows in ungauged basins. The next two papers deal with characterization of rainfall and streamflow. In their paper "Downscaling Monsoon Rainfall over River Godavari Basin under Different Climate-Change Scenarios" Das and Umamahesh 2016 address the problem of downscaling future monsoon rainfall making use of different climate scenarios, with specific reference to Godavari river in India. Using data from several GCM models, downscaling over the analysed basin is carried out through fuzzy clustering with multiple regression. Results indicate the feasibility of the proposed approach, which can find application in other regions. Portela and Silva 2016 present the article "Disaggregation Modelling of Annual Flows into Daily Streamflows Using a New Approach of the Method of Fragments", where they address the problem of stochastic generation of synthetic streamflows. They modified the method of fragments and applied it to the generation of synthetic daily flow series, discussing its relevance to analyse the uncertainty due to the temporal variability of the flow regime. In the paper "Rainfall-Runoff Model Considering Microtopography Simulated in a Laboratory Erosion Flume" Aksoy et al. 2016 present a process-based hillslope scale rainfall-runoff model that takes into account microtopography. Their model is validated on a laboratory scale erosion flume using a rainfall simulator. Results indicate that the developed model can be used as a ground for prediction of overland flow at hillslope scale and be extended to the watershed scale. The last articles in the section deal with groundwater. In their contribution "The Correlation Between Statistically Downscaled Precipitation Data and Groundwater Level Records in North-Western Turkey " Fistikoglu et al. 2016 present an approach to develop statistical relationships between large-scale atmospheric variables and local-scale meteorological variables. In particular, they make use of large scale atmospheric parameters published by National Center for Environmental Prediction and National Center for Atmospheric Research (NCEP/NCAR) climate dataset. They use statistical downscaling to fill the gaps in precipitation data obtained from a poorly operated meteorological station and correlate them to observed groundwater levels. Their results indicate the feasibility of the methodology to improve the short-term estimates of groundwater level predictions in a surficial alluvial aquifer. Finally, "Integrating Diffuse and Concentrated Recharge in Karst Models", by Kavouri and Karatzas 2016, presents a methodology to evaluate the contribution of distinct infiltration zones and examine different hypotheses on the spatial distribution of recharge zones. The applied methodology comprises two parts: i) the development of a 3D transient model and ii) the development and examination of different scenarios on the spatial distribution of recharge. This method is applied to the karst aquifer of Palaikastro-Chochlakies in Eastern Crete, Greece. The developed methodology can be applied to any unconfined karst system exhibiting spatial variability of their intrinsic properties. In large karstic terrains the spatial characterization of the aquifer is of great importance, considering that karstic areas may extend to tens of square kilometres.

The second section of this special issue deals with hydrologic extremes: floods and droughts. Floods are among the major disasters in mankind history, as shown by the fact that 
they were even recorded in the ancient scriptures of the Sumerians and in the holy books (e.g. the Big Flood during Prophet Noah). Flood disasters can be very devastating with huge unrepairable consequences, such as loss of lives, livelihoods and economic burden. This issue has become more important in recent decades, especially under climate change conditions. Thus, EWRA World Congress 2015 was focused on many aspects of floods. The first article is "Estimating Temporal Changes in Extreme Rainfall in Sicily Region (Italy)", by Bonaccorso and Aronica 2016. The authors apply regional frequency analysis, based on L-moments approach, for the annual maxima rainfall (AMR) series that are grouped per homogeneous regions and identified through a hierarchical cluster analysis. Mendes and Maia 2016 present the paper "Hydrologic Modelling Calibration for Operational Flood Forecasting". They develop a rainfall-runoff model carrying out daily simulations to predict flood flow. Their model allows the adjustment of the simulation model parameters to current weather and hydrological conditions of a river basin. In "Design and Application of an Adaptive Time Delay Model for Flow Routing in Prismatic Trapezoidal Geometry River Reach" Nguyen et al. 2016 propose an adaptive time delay model for flood routing in wide rectangular channels, using moment matching to derive the parameters of the model from the linearized Saint Venant equations. Their method can be utilized to simulate and design control strategies for river systems not influenced by backwater effect. The paper by Haltas et al. 2016, "Numerical Simulation of Flood Wave Propagation in Two-Dimensions in Densely Populated Urban Areas due to Dam Break", investigates the consequences of another flood type that can be caused by the break of a man-made structure, such as a dam. The authors eloquently present the methods for creating flood maps due to dam break. The methods include the creation of bathymetric, DEM and land use maps, routing of flood wave along a narrow valley using a 1D model and two dimensional numerical modelling of propagation and spreading of the flood wave.

Drought is another extreme weather condition which can have devastating impacts on social and economic welfare. Droughts, like floods, have also been a matter of concern in the history of mankind. Droughts are frequently cited in the holy books (e.g. seven years of drought period during Prophet Joseph), which suggests that this recurrent phenomenon has been severely experienced by people throughout history. Climate change in recent decades has also made the study of droughts very important. Several contributions to this special issue are focused on this topic. In their contribution "Analysing Drought Severity and Areal Extent by 2D Archimedean Copulas" Tsakiris et al. 2016 analyse droughts as two-dimensional phenomena, including drought severity and areal extent. For this purpose, they use the GumbelHougaard copula from the Archimedean family. Paulo et al. 2016 present "Influence of Precipitation Changes on the SPI and Related Drought Severity", where they carry out a comprehensive analysis of the influence of long-term precipitation variability on drought assessment by the SPI. In the article "Optimization of Hedging Rules for Reservoir Operation During Droughts Based on Particle Swarm Optimization “ Spiliotis et al. 2016 propose a methodology for identifying optimal hedging rules for operating a reservoir system, with the objective of mitigating drought impacts. For this purpose, they combine the particle swarm optimization method with the simulation model for the water resources system.

The final part of this special issue is focused on water management strategies covering topics from the general approach to details of implementation. Burak and Margat 2016 present the paper "Water Management in the Mediterranean Region: Concepts and Policies". They propose a new water shortage indicator to characterize water resources status and their management. They note that short-term goals have been frequently given priority over longterm environmental objectives, but a successful solution to this problem has not been found 
yet. Peres and Cancelliere 2016 address this topic in "Environmental Flow Assessment Based on Different Metrics of Hydrological Alteration", with a proposal for assessment of environmental flows to maximize the possible utilization of water while limiting the hydrologic alteration status. In their Sicilian case study, they found that the attainment of a low alteration target is quite demanding in terms of environmental flow allocation. Water uses have increased leading to competition for scarce water resources. This is the case of Lake Karla, analysed by Tzabiras et al. 2016 in "Evaluation of Water Resources Management Strategies to Overturn Climate Change Impacts on Lake Karla Watershed", where this problem is aggravated by climate change. After analysing many management strategies in the basin they found that the water deficit may become critical in the future. Technical solutions may improve management of complex systems. In "Pumping Optimization of Coastal Aquifers Assisted by Adaptive Metamodelling Methods and Radial Basis Functions“ Christelis and Mantoglou 2016 discuss the application of a novel optimization technique to the management of coastal aquifers, a complex problem of numerical analysis of variable-density flow and salt transport. Human pressure on the environment is also leading to the deterioration of water quality. In their contribution "Delineating Reservoir Protection Areas through Spatial Analyses in Support of Water Quality Protection” Gül and Onuşluel Gül 2016 shed some new light to the problem of water quality protection in drinking water reservoirs. They suggest a spatial approach for delineation of protection areas as an alternative strategy to prevent drinking water sources from contamination. Finally, the article "Effect of Operational and Design Parameters on Performance of Pilot-Scale Vertical Flow Constructed Wetlands Treating University Campus Wastewater", by Papaevangelou et al. 2016, deals with the problem of improving the technology for wastewater treatment systems. They studied three vertical-flow constructed wetland units to evaluate the influence of different feeding regimes, vegetation, temperature and seasonal variations on their performance. They obtained satisfying results as a first treatment stage for a wide range of hydraulic loads.

The articles in this collection demonstrate that water resources management is an active field of research, where new ideas are constantly emerging to face the challenges posed by the increasing complexity of water management. We believe that this special issue has contributed to EWRA goals and we are grateful to many people who made it possible. We would first like to thank the organization and the participants of the 2015 World Congress of EWRA for their enlightening presentations and active discussions during the congress. We thank the authors for their contributions and the reviewers for their useful and timely comments on the manuscripts submitted to this issue. Finally, we also like to thank the excellent editorial team of WARM for their effort and professional commitment.

\section{References}

Aksoy H, Gedikli A, Unal NE, Yilmaz M, Eris E, Yoon J, Tayfur G (2016) Rainfall-runoff model considering microtopography simulated in a laboratory erosion flume. Water Resour Manag. doi:10.1007/s11269-0161439-y

Bonaccorso B, Aronica GT (2016) Estimating temporal changes in extreme rainfall in Sicily region (Italy). Water Resour Manag. doi:10.1007/s11269-016-1442-3

Burak S, Margat J (2016) Water Management in the Mediterranean Region: concepts and policies. Water Resour Manag. doi:10.1007/s11269-016-1389-4

Christelis V, Mantoglou A (2016) Pumping optimization of coastal aquifers assisted by adaptive Metamodelling methods and radial basis functions. Water Resour Manag. doi:10.1007/s11269-016-1337-3 
Das J, Umamahesh NV (2016) Downscaling monsoon rainfall over river Godavari Basin under different climatechange scenarios. Water Resour Manag. doi:10.1007/s11269-016-1549-6

Fistikoglu O, Gunduz O, Simsek C (2016) The correlation between statistically downscaled precipitation data and groundwater level Records in North-Western Turkey. Water Resour Manag. doi:10.1007/s11269-0161313-y

Gül A, Onuşluel Gül G (2016) Delineating reservoir protection areas through spatial analyses in support of water quality protection. Water Resour Manag. doi:10.1007/s11269-016-1529-x

Haltas I, Elçi S, Tayfur G (2016) Numerical simulation of flood wave propagation in two-dimensions in densely populated urban areas due to dam break. Water Resour Manag. doi:10.1007/s11269-016-1344-4

Kavouri K, Karatzas GP (2016) Integrating diffuse and concentrated recharge in karst models. Water Resour Manag. doi:10.1007/s11269-016-1528-y

Mendes J, Maia R (2016) Hydrologic modelling calibration for operational flood forecasting. Water Resour Manag. doi:10.1007/s11269-016-1509-1

Nguyen LD, Karimanzira D, Rauschenbach T, Ribbe L (2016) Design and application of an adaptive time delay model for flow routing in prismatic trapezoidal Geometry River reach. Water Resour Manag. doi:10.1007 /s11269-016-1438-z

Papaevangelou V, Gikas GD, Tsihrintzis VA (2016) Effect of operational and design parameters on performance of pilot-scale vertical flow constructed wetlands treating university campus wastewater. Water Resour Manag. doi:10.1007/s11269-016-1484-6

Papageorgaki I, Nalbantis I (2016) Classification of drainage basins based on readily available information. Water Resour Manag. doi:10.1007/s11269-016-1410-y

Paulo A, Martins D, Pereira LS (2016) Influence of precipitation changes on the SPI and related drought severity. An analysis using long-term data series. Water Resour Manag. doi:10.1007/s11269-016-1388-5

Peres DJ, Cancelliere A (2016) Environmental flow assessment based on different metrics of hydrological alteration. Water Resour Manag. doi:10.1007/s11269-016-1394-7

Portela MM, Silva AT (2016) Disaggregation modelling of annual flows into daily streamflows using a new approach of the method of fragments. Water Resour Manag. doi:10.1007/s11269-016-1402-y

Spiliotis M, Mediero L, Garrote L (2016) Optimization of hedging rules for reservoir operation during droughts based on particle swarm optimization. Water Resour Manag. doi:10.1007/s11269-016-1285-y

Tsakiris G, Kordalis N, Tigkas D, Tsakiris V, Vangelis H (2016) Analysing drought severity and areal extent by 2D Archimedean copulas. Water Resour Manag. doi:10.1007/s11269-016-1543-Z

Tzabiras J, Vasiliades L, Sidiropoulos P, Loukas A, Mylopoulos N (2016) Evaluation of water resources management strategies to overturn climate change impacts on Lake Karla watershed. Water Resour Manag. doi:10.1007/s11269-016-1536-y 